artelogie

\section{Artelogie}

Recherche sur les arts, le patrimoine et la littérature de l'Amérique latine

1 | 2011

Brésil, questions sur le modernisme

\title{
Espaços de Paulo Prado: tradição e modernismo
}

\section{Thaís Chang Waldman}

URL: https://journals.openedition.org/artelogie/8482

DOI: 10.4000/artelogie.8482

ISSN: 2115-6395

\section{Editora}

Association ESCAL

\section{Refêrencia eletrónica}

Thaís Chang Waldman, «Espaços de Paulo Prado: tradição e modernismo», Artelogie [Online], 1 | 2011, posto online no dia 01 março 2011, consultado o 07 janeiro 2022. URL: http://

journals.openedition.org/artelogie/8482 ; DOI: https://doi.org/10.4000/artelogie.8482

Este documento foi criado de forma automática no dia 7 janeiro 2022.

Association ESCAL 


\title{
Espaços de Paulo Prado: tradição e modernismo
}

\author{
Thaís Chang Waldman
}

1 Ainda que freqüentemente mencionado em estudos sobre os anos 1920 e sobre o modernismo, figurando também em correspondências e notícias da época, pouco foi escrito sobre Paulo da Silva Prado (1869-1943). Além de alguns artigos, resenhas e capítulos em livros e verbetes, o que existe em termos de trabalho sistemático sobre Paulo Prado é o livro de Carlos Eduardo Ornelas Berriel, Tietê, Tejo, Sena: A obra de Paulo Prado (2000). Este trabalho quer pensar o problema da "dimensão de continuidade" que o modernismo comporta, mas que freqüentemente tem sido negligenciado em favor do "ato de ruptura" que os autores e as críticas praticaram ${ }^{1}$.

2 Se as idéias de Prado nem sempre são originais - no limite nenhuma é - ele aproveita os repertórios disponíveis a partir de uma ótica e de um lugar particulares, e é justamente aí que reside o seu interesse. Talvez seja possível - e mais interessante - deixar de lado a perspectiva analítica que tende a procurar "continuidades" e/ou "rupturas" nos autores e idéias, buscando enfrentar a atuação e produção de Paulo Prado de outro modo: em função da análise e descrição de grupos e situações no interior dos quais ele se formou, atuou e produziu. Com isso, Paulo Prado, o que ele fez e o que escreveu aparecem como elementos de mediação entre universos distintos, o que nos ajuda também a pensar as ambivalências de um período marcado por mudanças aceleradas.

Paulo Prado mostra-se um importante mediador entre universos aparentemente díspares e é exatamente nessa sua posição no "meio", entre grupos, tradições e gerações, que reside o interesse do presente trabalho. Prado aproxima-se de personagens e círculos à primeira vista antagônicos e opostos, como aqueles que integravam o Instituto Histórico e Geográfico de São Paulo - fundado em 1894 - e os jovens intelectuais e artistas ligados à Semana de Arte Moderna de 1922 - como Mário de Andrade (1893-1945) e Oswald de Andrade (1890-1954). Uma análise da personagem, de sua produção e atuação parece fornecer um acesso privilegiado para compreendermos, de modo mais localizado, uma cena de transição e para pensarmos, de modo mais amplo, as relações entre arte e ciência, entre literatura e história. 
4 Apesar de não existir uma biografia dessa personagem, os esboços biográficos, as correspondências trocadas, os depoimentos, as lembranças e as pequenas histórias contadas sobre Paulo Prado permitem uma melhor visualização do espaço que ele ocupa na grande teia de relações da época. As diversas facetas de sua identidade sofrem sucessivas alterações e incorporações em função dos espaços por ele ocupados.

Bisneto do Barão de Iguape, Paulo Prado foi criado no seio de uma tradicional família paulista ligada à produção do café. Em fins do século XIX, a família Prado não somente é a maior produtora de café da época, como também exerce importante papel na direção do país, nas campanhas da abolição e de imigração, assim como na lavoura, pecuária, indústria e transportes. Paulo Prado incorpora o capital familiar sob suas diversas formas - cultural, econômica, social e política - em um período de transição da Monarquia à República, da escravidão negra à mão-de-obra livre, do apogeu da exportação do café aos primórdios da industrialização. Graduado na última turma do Império, em 1889, vê desaparecer, com a proclamação da República, o ambiente que lhe é familiar, fechando-se as portas para a provável carreira política que teria seguido como primogênito da família ${ }^{2}$.

O contexto de mudanças experimentado por Paulo Prado faz com que ele possa ser visto como uma figura de "transição", representando o ponto de encontro de duas épocas e de duas mentalidades distintas. Mesmo no interior da própria família, ele convive com perfis muito diferentes uns dos outros. Por exemplo, enquanto a residência de seu pai, Antônio Prado (1840-1929), é freqüentada pelas principais figuras do Partido Conservador; seu tio, Martinho Prado Júnior (1843-1906), um dos futuros fundadores do Partido Republicano Paulista (PRP), entra em greve de fome na tentativa de conseguir permissão dos pais para se alistar como voluntário na Guerra do Paraguai ${ }^{3}$.

7 Aos 20 anos, logo após se graduar, Paulo Prado viaja pela Europa e se estabelece em Paris, junto ao tio, o jornalista monarquista Eduardo Prado (1860-1901), em um apartamento com vista para o jardim das Tulherias e para o Louvre ${ }^{4}$. Paulo Prado não apenas mimetiza a imagem de Eduardo, que jovem e abonado vai conhecer a Europa e se torna amigo de gente ilustre, como também se encanta com as figuras do diplomata, fazendeiro, historiador e jornalista, cultivadas pelo tio.

8 Paulo Prado confessa posteriormente que esse período foi o mais belo e feliz de sua vida: "Imagine você ! Eu, moço, com dinheiro no bolso, em Paris, assediado pelas mulheres, em vez de me deixar arrastar por elas, preferia ir pra Neuilly, ouvir o

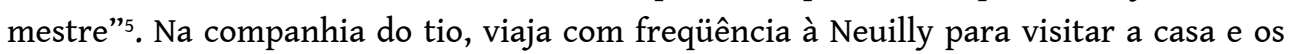
saraus do escritor português Eça de Queirós (1845-1900), que o descreve como um gentil rapaz interessado em "passear o seu diletantismo".

9 Uma das principais heranças que Eduardo Prado deixa ao sobrinho é sua ampla rede de amigos, que se reúne em Paris, apurando, na Europa, o patriotismo. São artistas, diplomatas e escritores brasileiros de passagem por Paris, assim como franceses e portugueses. As reuniões desse grupo no apartamento parisiense de Eduardo são fortemente marcadas por discussões de temas brasileiros, como a política atual, o sentido da história brasileira e o futuro do país ${ }^{7}$.

10 Distante do próprio país, Paulo Prado consegue enxergá-lo com mais interesse. 0 "culto da pátria ausente", explica ele, "conheci-o eu forte e constante nesse grupo de espíritos privilegiados". Ao freqüentar os mesmo círculos intelectuais que o tio, Paulo Prado aproxima-se não só de Eça de Queirós, mas também de Graça Aranha (1868-1931), 
Afonso Arinos de Melo Franco (1868-1916), Oliveira Martins (1845-1894), Barão do Rio Branco (1845-1912), Domício da Gama (1862-1925), Olavo Bilac (1865-1918) e Joaquim Nabuco (1849-1910), entre outros, quase todos ligados à vida diplomática.

11 É na companhia de Eduardo, Joaquim Nabuco e Barão do Rio Branco que Paulo Prado adquire o interesse por livros e manuscritos raros. Com eles começa a freqüentar, em 1893, a Livraria Americana, do antiquário Charles Chadenat (1855-1935), no Quai des Grands Augustins 9 . Chadenat, herdeiro do livreiro Dufossé, é um dos primeiros antiquários do século XIX a se especializar em obras sobre as colônias e ex-colônias européias. Sua livraria torna-se um dos pontos prediletos de Paulo Prado em Paris, um local para buscar raridades ou mesmo conversas com o "velho livreiro" que narrava "infindáveis discussões sobre história do Brasil"10.

12 Mas os encontros de Paulo Prado com essa roda de escritores e diplomatas não se restringem às reuniões na casa de Eduardo e nem às discussões acerca da história do Brasil. Em 1890, por exemplo, assiste, na companhia do tio, de Olavo Bilac e Domício da Gama, as homenagens ao décimo aniversário da morte do escritor Gustave Flaubert (1821-1880), em Rouen. Durante a viagem de Paris a Rouen, divide o vagão na primeira classe com os romancistas Émile Zola (1840-1902), Edmond de Goncourt (1822-1896) e Guy de Maupassant (1850-1893) ${ }^{11}$. Na mesma época, Paulo Prado viaja para Oberamergau, na Baviera, e assiste à representação decenal da Paixão de Cristo, na companhia do tio, de Domício da Gama e Afonso Celso (1860-1938) ${ }^{12}$.

Encantado com o Velho Mundo, Paulo Prado permanece na Europa por mais tempo do que a família gostaria. Posteriormente confessa que quando moço só a Europa o interessava, era a "terra prometida"13. Mas não tarda para que a mãe o aconselhe a ter uma vida mais regular. Em 1891, ela pede que o filho volte para São Paulo e assuma os negócios da família ${ }^{14}$. Seguindo os conselhos da mãe, Prado retorna a São Paulo e dedica-se com mais empenho à vida empresarial. Mas logo volta a morar em Paris. Em 1897, é a vez do pai se aborrecer e lhe ordenar que regresse ao Brasil imediatamente para administrar os negócios da família ${ }^{15}$. Prado obedece ao pai e fixa residência em São Paulo.

14 Sob a direção de Paulo Prado, a Companhia Prado Chaves torna-se a mais importante empresa exportadora de café de propriedade brasileira, fundando, entre 1908 e 1923 , subsidiárias em Londres, Hamburgo e Estocolmo. Além de destacar-se na direção da casa exportadora, Prado também passa pela diretoria da Companhia Paulista de Estradas de Ferro, a primeira ferrovia da província, construída para cobrir as novas regiões produtoras de café. Mas nem por isso abandona seu apreço por Paris, pelo requinte e pelas artes: transforma suas idas a Paris em temporadas anuais, nas quais, mantendo a elegância e os hábitos refinados, atravessa o Atlântico nas melhores embarcações e em cabines de luxo ${ }^{16}$.

15 É justamente em uma de suas temporadas na Paris das vanguardas, em 1918, que Paulo Prado começa a se corresponder com o historiador cearense Capistrano de Abreu (1853-1927), que ele conhecera anos antes, ao freqüentar os mesmos círculos intelectuais que Eduardo Prado. Guiado por Capistrano, que é considerado um marco da moderna historiografia brasileira, Paulo Prado enfatiza outra imagem de si mesmo, a de historiador, que será acompanhada pela de mecenas, não apenas das vanguardas, mas dos intelectuais em geral. juízos acerca da cultura brasileira. O "Paulo amigo" a quem se refere Capistrano é um 
de seus mais importantes correspondentes ${ }^{17}$. Essa troca de correspondências coincide exatamente com o período da escrita dos dois livros de Prado: Paulística, história de São Paulo (1925) e de Retrato do Brasil, ensaio sobre a tristeza brasileira (1928). Como Prado demonstrava grande interesse pelos primórdios da história de São Paulo, o diálogo entre os dois é freqüentemente marcado por esse tema. Inicialmente, a idéia da correspondência entre eles parte de Capistrano, que queria a ajuda financeira de Paulo Prado para retomar um projeto inacabado de seu tio Eduardo: a publicação de uma série de documentos e textos inéditos sobre os primórdios da colonização portuguesa. Segundo Capistrano, "Paulo Prado, sobrinho de Eduardo, é um rapaz culto. Atirado ao comércio, tem prosperado sem abandonar os livros. Preso em casa pela gota, leu meus Capítulos e ganhou amor à História. Sugeri que em honra do tio, cuja memória continua a estremecer, publicasse uns livros com o título Eduardo Prado. Aceitou a idéia, com a condição de escrever os prólogos este seu amigo"18.

Há aqui uma valorização do lado intelectual de Paulo Prado, que apesar do dinheiro e dos negócios herdados da família, não abandona os livros, a cultura, o saber. Capistrano, ao contrário, não possui a vantagem decisiva do capital econômico herdado, que o tornaria livre das sujeições oriundas da sobrevivência. Se em sua juventude Paulo Prado se beneficia do patrocínio da família para realizar suas viagens a Paris, agora, autônomo financeiramente, patrocina os amigos e colegas, seja Capistrano ou sejam os modernistas e pessoas de seus círculos.

Paulo Prado aceita a proposta de reativar parte do projeto inacabado de Eduardo, financiando a publicação de obras raras ou em estado manuscrito original que estivessem relacionadas ao passado histórico nacional. A coleção Eduardo Prado: para melhor conhecer o Brasil tem início junto a Semana de Arte Moderna. Os primeiros volumes, com prefácio de Capistrano, são publicados em 1922: o fac-similar de Histoire de la mission des pères capucins en l'isle de Maragnan et terres circunvoisines, do missionário capuchinho Claude d'Abbeville; e o livro Um visitador do Santo Ofício à Cidade do Salvador e ao recôncavo da Bahia de Todos os Santos 1591-92, que reúne depoimentos recolhidos na Primeira visitação do Santo ofício às partes do Brasil, pelo licenciado Heitor Furtado de Mendonça.Se, no final do século XIX, Paulo Prado conhece Capistrano de Abreu - a quem ele chamará diversas vezes de "Mestre" - por intermédio de seu tio, Eduardo Prado; é também Eduardo quem irá lhe apresentar, na mesma época, Graça Aranha. Anos depois, no início da década de 1920, Aranha colocará Paulo Prado em contato com os jovens modernistas que ele havia acabado de conhecer ${ }^{19}$. Isso indica, logo de saída, que o "grupo modernista" está longe de ser homogêneo, pelo contrário, há um evidente conflito de gerações, posições e postos. Rixas e divergências à parte, o meio cultural e intelectual é reduzido, e todos praticamente circulam pelos mesmos (e poucos) espaços.

Desse modo, com 53 anos na época, Paulo Prado figura ao lado de jovens intelectuais e artistas como personagem central do movimento que promove a Semana de Arte Moderna de 1922, no interior da qual, segundo suas próprias palavras: "com uma alegria iconoclasta e juvenil se quebram os antigos moldes e desaparecem as velhas regras, pesadas como grilhões" ${ }^{20}$. Não só o nome de Paulo Prado é o primeiro a aparecer na lista dos financiadores da Semana, como é ele também quem se encarrega do programa, da divulgação e dos demais detalhes para que o evento, no Teatro Municipal, tivesse um alcance retumbante ${ }^{21}$.

21 O evento é patrocinado por figuras pertencentes às tradicionais elites do estado: cafeicultores, fazendeiros, banqueiros e empresários nascidos na segunda metade do 
século XIX. Um círculo endinheirado e requintado, entre eles Paulo Prado. Com seu prestígio, explica Mário de Andrade, Prado "abr[e] a lista das contribuições e arrast[a] atrás de si os seus pares aristocratas e mais alguns que sua figura dominava" ${ }^{22}$. Além disso, ajuda financeiramente os participantes do evento, como o artista plástico Emiliano Di Cavalcanti (1897-1976) que, por ocasião da Semana, desabafa a Mário e Oswald de Andrade: "não é vergonha ser pobre e ser boêmio, digam logo a Paulo Prado que me falta dinheiro para pagar o hotel, e que ele compre uns desenhos meus, um quadro, o que ele quiser, para me sustentar aqui em São Paulo, por um mês" ${ }^{23}$.

A imagem da Semana de Arte Moderna como um marco na renovação cultural do país ${ }^{24}$ tem sido, já há alguns anos, criticada por estudos que procuram atenuar seu caráter de ruptura ${ }^{25}$. No entanto, embora muitos autores já tenham se debruçado sobre o tema, interrogando criticamente o significado do modernismo de São Paulo para a história da literatura brasileira, o fato é que a Semana agitou o ambiente paulista.

Cândido Motta Filho relembra um diálogo no qual o poeta Ronald de Carvalho comenta que a "reunião modernista" estava "cheia de passadistas", ao que Paulo Prado teria respondido: "isso não tem importância. 0 importante é a reunião !" 26.0 primordial era desafiar um gosto consolidado com algo diferente daquilo que a Academia ensinava ou, ao menos, tentar fazê-lo. Nesse sentido, se a intenção deliberada do evento era chocar, de fato, a platéia saiu de lá, no mínimo, incomodada, como demonstram as vaias e gritos de desaprovação. Inclusive, conta Geraldo Ferraz, era Paulo Prado quem gritava, ao calor das vaias do público, sugestões para dominar o alvoroço e prosseguir sem problemas com o evento ${ }^{27}$.

24 Ainda que não tenha produzido nada de substancial ou representativo por ocasião da Semana de Arte Moderna, e que sua obra seja realizada no campo do ensaio, e não no da literatura ou das artes plásticas, que constituem o núcleo do movimento, Paulo Prado é reiteradamente aclamado como quem deu expressão e visibilidade ao evento. Ninguém melhor que ele, portanto, para ser o verdadeiro "fautor" da Semana de Arte Moderna, indica Mário de Andrade em um balanço do evento, vinte anos após o mesmo: "o fautor verdadeiro da Semana de Arte Moderna foi Paulo Prado. E só mesmo uma figura como ele e uma cidade grande, mas provinciana como São Paulo, poderiam fazer o movimento modernista e objetivá-lo na Semana"28. Tudo isso rende a Paulo Prado a imagem do grande "promotor" do evento, conforme explica Oswald de Andrade, também em um balanço posterior da Semana: "sem a inteligência e a compreensão de Paulo Prado, nada teria sido possível. Ele foi o agente de ligação entre o grupo que se formava e o medalhão Graça Aranha" ${ }^{29}$. Oswald ressalta a importância de Prado para a sociabilidade intelectual do "grupo", já que "ele colocava em sua frente Graça Aranha (...), filho duma abominável formação filosofante do século XIX, mas grande homem nacional, pertencente a nossa Academia de Letras, e autor de um livro tabu "Canaan", que ninguém havia lido e todos admiravam"30.Autor de Canaã (1902), já um clássico na década de 1920, Graça Aranha daria legitimidade ao movimento. Diante desse quadro, Paulo Prado pode ser considerado como um mediador entre diferentes tendências, seja entre o "grupo que se formava" e o "medalhão Graça Aranha", ou mesmo dentro do próprio "grupo que se formava". Por ocasião da Semana de Arte Moderna, Aranha - de quem Prado havia se aproximado ainda no século XIX - não só mantém um casamento extra-oficial, porém público, com Nazareth Prado, irmã de Paulo, como também participa dos empreendimentos da família Prado ${ }^{31}$. 1922 toma também o campo das relações pessoais. Lembremos que Prado é padrinho 
por parte da noiva, ao lado de Olívia Guedes Penteado, do casamento de Oswald de Andrade e Tarsila do Amaral, em 1926. Além disso, Oswald não somente é prefaciado por Prado em sua Poesia Pau Brasil (1925), como lhe dedica Memórias Sentimentais de João Miramar (1924); enquanto Mário confessa em um prefácio inédito ter escrito Macunaíma (1928) a partir da leitura dos rascunhos de Retrato do Brasil, lançado no mesmo ano. Temos aí constituída "uma parceria de afinidades que sinalizam o lastro social no qual se entranhava o entrosamento ideal perseguido pelos modernistas, entre cultura, política e mundanismo" 32 .

Lembremos que Paulo Prado teve também atuação decisiva em vários episódios que atuaram como prelúdios da Semana de 1922. A maioria dessas atividades públicas por ele organizadas e financiadas foram realizadas no Teatro Municipal de São Paulo, cuja construção representa uma grande marca da administração de seu pai como prefeito da cidade $^{33}$. São Paulo, dizia Antônio Prado, "não tinha vida social. Era necessário estimulá-la intensamente, por todos os meios e em todas as classes da população. Sem o que nunca passaria de um quieto burgo do interior" ${ }^{\prime 3}$.

O projeto do teatro paulistano foi encomendado a Cláudio Rossi (1850-1935), arquiteto da família Prado, que teve que viajar à Europa para pesquisar e adquirir o material apropriado. Construído em um terreno que pertencia a Companhia Antártica Paulista, ligada empresarialmente a família Prado, que lhe fornecia os vasilhames da Vidraria Santa Marina, o Teatro Municipal de São Paulo tornou-se um reduto privilegiado de eventos de atualização da consciência artística e cultural, que têm lugar anos antes da famosa Semana de Arte Moderna ${ }^{35}$.

As instalações do teatro paulistano contarão não apenas com a apresentação de óperas clássicas, mas também de bailados modernos como os de Isadora Duncan (1877-1927), em 1916, Vaslav Nijinski (1889-1950), em 1917 e 1918, e Anna Pavlovna (1881-1931), em 1918 e 1919. Além disso, a Orquestra Sinfônica Italiana, sob a regência do maestro Gino Marinnuzzi (1882-1945), reunirá em um mesmo programa, em 1919, Debussy (1862-1918), Respighi (1879-1936) e Wagner (1813-1883). Essa seqüência terá prosseguimento com Arthur Rubinstein (1887-1982), em 1920 e 1922, executando ao piano Stravinsky (1882-1971), Debussy e Villa Lobos, entre outros, e também com a pianista Luba d'Alexandrowska, apresentando Ravel (1875-1937) e Debussy, em $1921^{36}$.

Paralelamente às iniciativas nas áreas musical, cenográfica e coreográfica, Paulo Prado, em colaboração com o senador Freitas Valle (1870-1958) e com o dramaturgo e poeta francês Paul Claudel (1868-1955) - com quem ele já havia negociado o Convênio FrancoBrasileiro $^{37}$-, instala no Teatro Municipal de São Paulo, em 1919, a Exposição de Pinturas e Esculturas Francesas. A parte de pintura, segundo Sevcenko (Ibidem), é fraca, mas a de escultura é representada por Antoine Bourdelle (1861-1929), Auguste Rodin (1840-1917) e Henri Laurens (1885-1954).

30 Tal exposição irá coroar um momento exemplar de modernização da consciência cultural e artística brasileira, pois ainda que a Pinacoteca do Estado, primeiro museu da cidade, inaugurado em 1905, já possuísse um acervo de pinturas e esculturas, ele estava mais voltado para a arte brasileira do século XIX ${ }^{38}$. É importante ressaltar que se a presença do presidente do Estado, do prefeito e respectivos altos escalões nessas exposições era freqüente, quem efetivamente patrocinava os artistas locais era "um apanágio de patronos abastados" ${ }^{39}$, como é o caso de Paulo Prado.

31 Além de contar com exposições e espetáculos estrangeiros, que reforçariam a imagem da cidade progressista à européia, o Teatro Municipal de São Paulo, no final da década 
de 1910, abrirá espaço para a monumental montagem dramático-musical 0 Contratador de Diamantes, baseada na obra póstuma de Afonso Arinos. Contemporâneo de Paulo Prado no Largo São Francisco, Arinos posteriormente tornou-se seu cunhado, ao casar-se com Antonieta Prado; recebeu também de Eduardo Prado a direção do jornal monarquista 0 Comércio de São Paulo, em 1897, e o substituiu na cadeira número 40 da Academia Brasileira de Letras. Desse modo, temos uma encenação que não só irá trazer para a ordem do dia o nome de Arinos, como também - e principalmente-, revelará um novo cenário cultural que se desenhava com a ajuda fundamental da família Prado.

A peça irá envolver os Prados e as principais famílias da elite paulista como patronos e mesmo como atores de uma representação ficcional da saga dos bandeirantes. No lugar de profissionais, atuam na peça os próprios membros das elites paulistanas, como: Antonieta Penteado Prado, irmã de Paulo; Eglantina Penteado Prado, sua cunhada; e o futuro historiador Caio Prado Júnior (1907-1990), seu sobrinho, ainda com 15 anos, representando no espetáculo seus supostos antepassados fundadores da pátria ${ }^{40}$. É curioso notar que todo o luxuoso mobiliário e a prataria de época utilizados na peça são parte do próprio patrimônio das famílias Prado e Penteado ${ }^{41}$.

33 Sucesso de público e de crítica, a peça ganhará destaque, em um tom de escândalo, para a apresentação da congada com dançarinos "pretos de verdade" ao lado de violeiros "autênticos da roça", como os definiu o jornal O Estado de S. Paulo ${ }^{42}$. Assim, o palco do Teatro Municipal de São Paulo, em 1919, já inicia, com a ajuda dos Prados, uma valorização do "popular", do "folclórico" e do "colonial", elementos chaves do programa modernista posterior.

34 Alguns meses antes de iniciar sua correspondência com o historiador Capistrano de Abreu, Paulo Prado adquire um quadro na histórica exposição de Anita Malfatti, em 1917, travando, ao que parece, seu primeiro contato com os futuros participantes de Semana de Arte Moderna. Esse contato com os jovens brasileiros será aprofundado em Paris, o que não soa estranho. Afinal, os arredores da Place de Clichy, no início do século XX, se transformam, nos termos de Paulo Prado, no "umbigo do mundo"43.

Na década de 1920, Paris e sua efervescência cultural atraíam artistas e mecenas de todos os lugares do mundo. No caso dos artistas brasileiros, lá estavam Di Cavalcanti, Tarsila do Amaral (1886-1973), Anita Malfatti (1889-1964), Victor Brecheret (1894-1955), Heitor Villa-Lobos (1887-1959) e Vicente do Rego Monteiro (1899-1970), entre outros, muitos deles patrocinados por Paulo Prado, como Brecheret, Di Cavalcanti e VillaLobos. Paulo Prado aparece aqui, já em idade madura, como um importante mediador entre São Paulo e Paris.

36 Ninguém mais do que Paulo Prado, contam os amigos, apreciava os prazeres da vida parisiense: o ateliê do pintor Fernand Léger (1881-1955), os quadros de Pablo Picasso (1881-1973) da casa de Madame Eugenia Errazuriz (1858-1951) e as obras prémodernistas do marchand Ambroise Vollard ${ }^{44}$. Prado chega a escrever uma carta de Paris a Mário de Andrade (1893-1945) só "para fazer inveja", pois estava "em frente a dois grandes Picassos, que são um encanto" ${ }^{45}$.

Ainda em Paris, na década de 1920, Paulo Prado conhece Gilberto Freyre (1900-1987), quando este realizava uma longa viagem pela Europa. Juntos, freqüentam os mais refinados restaurantes europeus e se tornam amigos íntimos ${ }^{46}$. De volta ao Brasil, Freyre passa a freqüentar assiduamente a casa de Prado em São Paulo, seu apartamento no Rio de Janeiro e a fazenda da família em Ribeirão Preto, a São Martinho, onde entra em contato com o passado rural de São Paulo e escreve parte de sua obra ${ }^{47}$. Anos depois, 
inclusive, Prado doa para Freyre os manuscritos do Diário Íntimo do engenheiro Louis Léger Vauthier, arrematados em um leilão em Paris. Diante dos manuscritos, Freyre publica Um Engenheiro Francês no Brasil (1940) e o dedica a Prado em sua segunda edição.

Mantendo o diletantismo do jovem interessado pelo próprio país, Paulo Prado irá atuar como uma espécie de agente civilizador. Tal imagem já vinha despontando desde 1917, quando Prado recebe do governo francês a medalha da Legião da Honra, instituída por Napoleão Bonaparte para recompensar os méritos militares ou civis à nação francesa. Prado recebe a mais alta condecoração francesa por ocasião do Convênio FrancoBrasileiro, que ele negocia com o dramaturgo e poeta francês Paul Claudel, Encarregado dos Negócios da França no Brasil.

Ao longo de suas diversas temporadas européias, Paulo Prado leva para o Brasil telas de Pablo Picasso, Fernand Léger, Francis Picabia (1879-1953) e Georges Rouault (1871-1958), que irão compor seu acervo pessoal em São Paulo ${ }^{48}$. Traz também de Paris, com a ajuda de Tarsila do Amaral e de Olívia Guedes Penteado (1872-1934), doze telas modernistas que irão fazer parte de uma exposição em São Paulo. Entre elas, constam não só obras de Léger e Albert Gleizes (1881-1953), que no período davam aulas à Tarsila, como também de Paul Cézanne (1839-1906), Lasar Segall (1891-1957), Robert Delaunay (1885-1941) e da própria Tarsila ${ }^{49}$.

O envolvimento de Paulo Prado e de Olívia Penteado com a comercialização de café no exterior - já que ambos são sócios de casas comissárias com filiais e frentes européias acaba por refinar-lhes o gosto para a arte moderna, tornando-os mais sensíveis às linguagens das vanguardas artísticas ${ }^{50}$. Essa inserção econômica particular, que impõe deslocamentos regulares para o exterior, abre novos horizontes no plano da atividade cultural, o que permite que os dois tragam para o Brasil as novidades encontradas na Europa.

41 Assim como Paulo Prado, Olívia Penteado tinha um grande apreço por Paris, pelo requinte e pelas artes. É lá inclusive que os dois se conhecem. Viúva de um grande exportador de café, Inácio Penteado, dono de uma agência comissária com filial no porto de Havre, Olívia freqüentava, desde jovem, o meio parisiense. No entanto, é somente na década de 1920 que conhece Paulo Prado. Juntos, visitam ateliês e marchands parisienses. Segundo depoimento de Oswald de Andrade, "[Olívia] não foi, em absoluto, uma 'snob'; tinha gosto. Uma influência decisiva sobre ela talvez fosse Paulo Prado, seu grande amigo. Ela se esclareceu quanto à arte moderna, em nossa companhia, em Paris"

Mais do que "esclarecer" Olívia, Paulo Prado parece querer estabelecer uma mediação entre as elites conservadoras do Brasil e a renovação estética parisiense. Assim, tornase o primeiro a trazer para o país uma tela cubista, um quadro de seu amigo Fernand Léger $^{52}$, que ironicamente será pendurado de cabeça pra baixo em seu salão ${ }^{53}$. Paulo Prado se aproxima de Léger provavelmente por intermédio de Tarsila do Amaral e Oswald de Andrade. Ao lado de suas respectivas companheiras, Prado e Léger são vistos com freqüência em Paris, quase sempre acompanhados pelo poeta de vanguarda Blaise Cendrars (1887-1961) $)^{54}$. Nesse sentido, não parece exagerado afirmar que o ingresso no círculo dos artistas modernistas brasileiro em Paris amplia as relações de Prado, que é introduzido a novos e importantes personagens da cena cultural européia.

Na já mencionada Livraria Americana de Paris - que Paulo Prado começa a freqüentar ainda jovem com os amigos do tio Eduardo -, Oswald de Andrade irá pedir que Prado convide Blaise Cendrars para conhecer o Brasil. Aceito o pedido, Prado financia a viagem de Cendrars, em 1924, hospedando-o durante seis meses em sua casa, e o 
convida para retornar ao país em duas outras ocasiões, em 1926 e 1927. Desse modo, Prado não apenas patrocina a viagem de modernistas brasileiros à Europa como também a de estrangeiros para o Brasil.

A bordo do navio Le Formose, que o levara da França para o Brasil, Blaise Cendrars escreve os poemas que compõem seu livro Feuilles de Route-1-Le Formose (1924), ilustrado por Tarsila do Amaral e dedicado a Paulo Prado e a seus "amigos modernistas". Na fazenda de Prado, Cendrars tenta concluir seu romance Moravagin (1926). Ainda em São Paulo, redige um capítulo de Les Confessions de Dan Yack (1929). Escreve também, nas temporadas brasileiras, os poemas Sud-Américaines (1926). É também através de Prado que Cendrars conhece pessoalmente Capistrano de Abreu, a quem irá homenagear na epígrafe de Une Nuit dans la Forêt (1929) e em “Utopialand, le pays qui n'est à personne ", de Trop c'est Trop (1957), com a citação de um canto fúnebre Bacaeri recolhido pelo historiador cearense ${ }^{55}$.

Blaise Cendrars também dedica a Paulo Prado o texto "Éloge de la Vie Dangereuse" (1926) - publicado em Aujourd'hui (1931) - escrito durante uma viagem que fizeram juntos a Praia Grande. o lobisomem dessa história é inspirado em um episódio observado por Cendrars quando viajava com Prado e seus amigos modernistas pela cidade de Tiradentes. Trata-se da famosa "caravana modernista de (re)descoberta do Brasil", que percorreu as cidades históricas mineiras em 1924: a Semana Santa em Tiradentes, seguindo depois para Água Santa, Mariana, Ouro Preto, Divinópolis, Sabará, Belo Horizonte e Congonhas.

Paulo Prado aproveita a presença de Blaise Cendrars no Brasil para lhe propor um ciclo de três conferências pagas no auditório do Conservatório Musical de São Paulo, o que daria certa autonomia financeira ao poeta ${ }^{56}$. Ao divulgar as conferências, procura, mais uma vez, enfatizar a tarefa de promover a atualização cultural brasileira: "os que forem à sua conferência ouvirão sem dúvida coisas novas, sairão da rotina cediça das administrações consagradas, perceberão a existência de um mundo desconhecido-'terra ignota'-, onde se elabora o grande renascimento do espírito criador" ${ }^{27}$.

A primeira conferência seria sobre poesia moderna ${ }^{58}$; a segunda sobre literatura negra, extraída de sua própria Anthologie Nègre (1921); e a terceira, uma "conferênciaexposição" sobre tendências gerais da estética contemporânea, na qual seriam expostas telas de Delaunay, Gleizes, Léger, Segall, Cézanne e Tarsila. Essas telas faziam parte do acervo de Paulo Prado, Olívia Penteado e Tarsila do Amaral, que apresentaria ao público seu primeiro quadro "Pau Brasil", o "E.F.C.B" (Estação de Ferro Central do Brasil)59, pintado justamente para a conferência de Cendrars ${ }^{60}$.

No ano seguinte, por sugestão de Blaise Cendrars, Oswald de Andrade irá publicar sua Poesia Pau Brasil (1925) em Paris, pela editora Au Sans Pareil, dirigida por René Hilsum, amigo de Cendrars. O livro de Oswald é prefaciado por Paulo Prado, que escreve de Paris, o que rende ao autor de Paulística - lançado no mesmo ano que a Poesia Pau Brasil -, a imagem do "primeiro paterno protetor da poesia nacional", conforme a dedicatória manuscrita de Oswald ${ }^{61}$. De volta à França, Blaise Cendrars mantém uma troca de correspondências constante com Paulo Prado, nas quais reclama da necessidade de "mato virgem" e da distância que o separa do amigo "Paul", descrito como um irmão 25 anos mais velho ${ }^{62}$. O Brasil "absorvia" o poeta: "Vous ne voyez pas le danger ? Déjà vous êtes à moitié Brésilien. Prenez garde !", previne-lhe Prado. Também por meio de correspondências, Cendrars irá divulgar o país a Le Corbusier (1887-1965), um dos grandes pioneiros da arquitetura moderna mundial, comentando inclusive os 
planos do governo brasileiro quanto a construção de uma nova Capital Federal: "em uma região ainda virgem" ${ }^{63}$.

Ao aproximar-se do arquiteto, por intermédio de Blaise Cendrars, Paulo Prado encontra outra oportunidade para atuar como agente civilizador. Assim, ao lado da escritora argentina Victoria O'Campo (1890-1979) - que Le Corbusier também conhece por intermédio de Cendrars - Prado encoraja o arquiteto a conhecer a América Latina e, em 1929, oficializa o convite para que ele realize palestras sobre arquitetura e urbanismo em Buenos Aires, São Paulo e Rio de Janeiro ${ }^{64}$.

O período brasileiro da viagem de Le Corbusier é financiado por Paulo Prado, que também o hospeda em sua casa. As conferências que Le Corbusier realiza no Rio de Janeiro e em São Paulo se transformam em um grande evento sociocultural. Em meio a auditórios lotados, estavam os arquitetos Gregori Warchavchik (1896-1972) e Rino Levi (1901-1965), que já haviam assumido a bandeira da arquitetura moderna no Brasil. o arquiteto Lucio Costa (1902-1998), anos depois, afirma ter também tentado assistir as palestras no Rio de Janeiro, mas “(...) a sala estava toda tomada”, explica ele ${ }^{65}$.

51 Além de palestrar, Le Corbusier é apresentado ao irmão de Paulo Prado, o prefeito do Rio de Janeiro Antônio Prado Júnior, que tinha planos de remodelar a cidade. 0 arquiteto apresenta ao prefeito um plano urbanístico em curva, que acompanharia a paisagem acidentada do Rio de Janeiro ${ }^{66}$. Famoso por receber encomendas de projetos residenciais em Paris, Le Corbusier chega também a elaborar um projeto visando à reformulação da casa de Paulo Prado, na Avenida Higienópolis, sob a supervisão de Warchavchik, mas como Paulo e sua esposa, Marie Noemi Alphonsine Lebrun - mais conhecida como Marinette -, não paravam em casa, o projeto é abandonado ${ }^{67}$.

Paulo Prado e Marinette começam a viver juntos por volta de 1920, quando a residência do casal em São Paulo, na Avenida Higienópolis, transforma-se em um importante centro de formação e de experimentação cultural dos setores de elite. Aos domingos, seus almoços tornam-se ponto de encontro de intelectuais, artistas plásticos e poetas, que lá encontram livros, revistas e obras recém trazidas da Europa. Ao redor da mesa de almoço, Paulo Prado apresenta-se como um importante mediador entre a sua geração, a geração anterior a sua e a dos jovens modernistas brasileiros de São Paulo e do Rio de Janeiro.

53 Segundo Mário de Andrade, o salão de Paulo Prado era o mais selecionado do período e o que teve duração mais longa ${ }^{68}$. Oswald de Andrade vai mais longe e afirma que foi durante esses almoços de domingo "faustosos" - onde se comia e bebia "dentro de uma grande tradição civilizada" e se debatiam "os problemas candentes a transformação das letras e das artes"-, que se "elaborou" o Modernismo ${ }^{69}$.

54 Na ausência de instituições culturais em São Paulo, Paulo Prado, ao lado de Olívia Guedes Penteado, destaca-se não apenas como anfitrião, mas também como promotor da arte moderna. Olívia, mesmo após a morte do marido, procura manter sua vida regrada pela etiqueta e pelos hábitos de luxo adquiridos em Paris e, a exemplo das damas da sociedade francesa, reserva, assim como Prado, um dia da semana, "le jour de Madame Penteado", para receber amigos, artistas e intelectuais em seu salão ${ }^{70}$. Ao lado do palacete de Prado, o de Olívia, localizado à Rua Conselheiro Nébias esquina com a Duque de Caxias, adquire um brilho excepcional no início do século XX.

55 Ainda que as casas de Paulo Prado e a de Olívia Penteado fossem freqüentadas pelos mesmos círculos intelectuais, na de Olívia há uma predominância de literatos e artistas, 
já na de Prado se reúnem também historiadores, como Capistrano de Abreu e Yan de Almeida Prado (1898-1987). Desse modo, na casa de Olívia ouve-se falar mais de arte e, particularmente, de pintura; já na de Prado a conversa vai de Proust à fundação do Partido Democrático, passando pela Semana de Arte Moderna e pelos problemas do café $^{71}$.

Os acervos trazidos da Europa por Paulo Prado e por Olívia Penteado continham uma mostra significativa dos artistas modernos da Escola de Paris, que terão grande impacto nos artistas ligados ao modernismo brasileiro: ilustrações e gravuras de André Derain (1880-1954), Gallanis (1880-1966) e Dunoyer de Segonzac (1884-1974); esculturas de Constantin Brancusi (1876-1957); pinturas de Georges Braque (1882-1963), Juan Gris (1887-1927), Henri Matisse (1869-1954), Amedeo Modigliani (1884-1920), André Lhote (1885-1962), Léger, Picasso, entre outros ${ }^{72}$.

A coleção de Paulo Prado, no entanto, não inclui apenas pintores internacionais ligados às vanguardas, mas também artistas brasileiros modernos. Durante a controvertida exposição de Anita Malfatti, em 1917, por exemplo, Prado adquire o quadro "A Onda" 73 . Pertencem também a ele os quadros "São Paulo"74 e "O Ovo" 75 , ambos de Tarsila do Amaral; além das esculturas "Cabeça de Mulher"76 - exposta durante a Semana de Arte Moderna -, "Safo"77, "Virgem"78 e "Ritmo"79, todas de Brecheret; e a tela "Sonho de uma Prostituta" ${ }^{80}$, de Cícero Dias (1907-2003), que Prado expõe no 1ํSalão de Maio ${ }^{81}$.

A atuação de Paulo Prado como colecionador de arte moderna no Brasil é fundamental no período. Ainda que os artistas da primeira geração modernista fizessem parte do mesmo círculo de convivência, conhecendo-se e se fazendo reconhecer como integrantes das elites, faltava consistência ao mercado local das artes. 0 principal comprador era o poder público, que negociava suas aquisições politicamente, sem grandes compromissos, atendendo os diversos lobbies comunitários e estilísticos de São Paulo ${ }^{82}$.

59 Assim, quando Paulo Prado efetua a única compra em uma exposição de Candido Portinari (1903-1962), o pintor doa-lhe outras duas obras como forma de agradecimento ${ }^{83}$. Mário de Andrade explica a importância e repercussão dessas obras compradas por Prado: "ora, um quadro comprado pelo Paulo Prado significa não raro uns três ou quatro vendidos, de indivíduos que vão na onda dele como Thiollier e de outros que criam coragem" ${ }^{84}$.

60 Como desdobramento da Semana de Arte Moderna, são lançadas diversas revistas de divulgação da produção modernista e o nome de Paulo Prado aparece muitas vezes associado à fundação e ao controle de boa parte dessas publicações. Seu nome já aparece, inclusive, logo na primeira revista modernista do Brasil, a Klaxon- Mensário de Arte Moderna, que começa a circular em 1922, no mesmo ano em que é lançada a Série Eduardo Prado: para melhor conhecer o Brasil.

61 Além de integrar o grupo da Klaxon, Paulo Prado também ajuda financeiramente a edição, embora tivesse a intenção de substituí-la por uma nova revista, a Knock-out. Editada por Paulo Prado e Tarsila Amaral, a Knock-out teria a colaboração de grandes nomes europeus, entre eles Blaise Cendrars, Ivan Goll (1891-1959), Marc Chagall (1887-1985) e Jean Cocteau (1889-1963). Mas apesar do encerramento da Klaxon, em 1923, a Knock-out não chega a ser publicada.

62 Paulo Prado assume em seguida o controle da Revista do Brasil, uma das publicações brasileiras de maior repercussão e longevidade no início do século XX. Idealizada em 
1915 por Júlio de Mesquita (1962-1927), jornalista e também proprietário do jornal 0 Estado de S. Paulo, a Revista do Brasil é controlada de 1918 a 1925 pelo escritor Monteiro Lobato. Devido ao sucesso da publicação, Lobato funda a editora Monteiro Lobato \& Cia que conta com a colaboração financeira de Prado na montagem do parque gráfico - e, como sabido, revoluciona o mercado editorial brasileiro ${ }^{85}$. Nesse período, entre 1923 e 1925, enquanto Lobato concentra seus esforços na editora, a Revista do Brasil passa a ser dirigida por Prado.

63 É justamente ao assumir a função de Monteiro Lobato que Paulo Prado, mantendo um diálogo constante com Capistrano de Abreu, escreve os ensaios que irão compor a primeira edição de Paulística, publicada em 1925, ao mesmo tempo em que assina os editoriais dos números 86, 87, 88, 89, 98, 99, 100 e 101 da Revista do Brasil. Sob sua direção, a Revista do Brasil, antes um órgão de cunho mais acadêmico, a princípio indiferente e depois até mesmo ligeiramente hostil aos modernistas, passará a simpatizar com o movimento ${ }^{86}$. Lobato confessa que ao deixar a revista nas mãos de Prado queria "ultramodernizá-la" e, acrescenta ele, "se não houver baixa no câmbio das assinaturas, o modernismo está aprovado" ${ }^{87}$.

Junto a Antônio de Alcântara Machado (1901-1935), Couto de Barros (1896-1966) e Sérgio Milliet (1898-1966) - assim como ele, ex-integrantes do grupo da Klaxon -, Prado também funda e financia a segunda revista modernista de São Paulo, a Terra Roxa e outras terras, em janeiro de 1926. Assim, no mesmo ano em que começa a escrever seu Retrato do Brasil e que participa da fundação do Partido Democrático de São Paulo (PD) ao lado do pai - um dos grandes responsáveis pela criação do partido e seu primeiro presidente -, Paulo Prado funda e financia uma revista que já em seu título afirma o predomínio paulista.

Alguns anos depois, em 1931, Paulo Prado novamente se associa a Alcântara Machado e Mário de Andrade. Juntos fundam a Revista Nova, também divulgadora das idéias modernistas. Segundo Mário, o objetivo da revista era publicar "muito pouca literatura, pelo menos literatura gratuita. Muita crítica e muitos estudos de qualquer ordem que tenham imediata correlação com o Brasil" ${ }^{88}$. No entanto, a publicação dura pouco mais de um ano, devido a "muita literatura gratuita" e pouco financiamento ${ }^{89}$.

Mesmo que muitos desses periódicos modernistas não tenham sobrevivido mais do que alguns poucos números, pode-se dizer que a eles fizeram parte o cotidiano da população letrada, assumindo um importante papel na vida intelectual paulista, que naquele momento era dominada pela "grande imprensa", principal instância de produção cultural da época ${ }^{90}$. Paulo Prado, além de ter seu nome associado à publicação e ao controle de publicações modernistas, também consagra e veicula sua produção intelectual em importantes jornais da "grande imprensa", como Correio da Manhã, Correio Paulistano, Jornal do Comércio, O Estado de S. Paulo e O Jornal. Os assuntos abordados por ele são os mais variados, tendo como foco principal São Paulo, seja do ponto de vista da arte moderna ou da agricultura, passando pelas forças armadas, educação e pecuária.

Ainda que Paulo Prado tenha escrito poucos textos, tais escritos são obras de uma vida. Por ocasião da publicação de seus dois únicos livros, Prado já contava com mais de 50 anos de idade. Esse aparente detalhe é fundamental, pois indica que o autor publica sua obra somente após uma longa interlocução com os mais diversos círculos por ele freqüentados. Prado aparece, todo o tempo, como um importante mediador, que se 
constrói no diálogo com suas diferentes facetas, estabelecendo interlocuções variadas com a vanguarda, a tradição, a arte, a história, a literatura, a política e a vida mundana.

A inserção em distintos círculos e a atuação em frentes e ramos muito diversos marcaram a trajetória de Paulo Prado. Além de ser um dos principais produtores e exportadores de café entre fins do século XIX e as primeiras décadas do século XX, Prado publicou dois volumes de interpretação histórica sobre a formação da nação e do povo brasileiro; (re)editou documentos inéditos sobre a história colonial brasileira; trouxe para São Paulo as novidades das vanguardas artísticas européias, adquiridas em suas temporadas anuais em Paris; financiou viagens de artistas e intelectuais modernistas, brasileiros e estrangeiros; publicou artigos sobre a situação política, financeira, cultural e artística do incipiente século XX em importantes periódicos paulistas; participou da fundação e do controle de revistas; e, por fim, marcou presença como um dos principais organizadores e financiadores da Semana de Arte Moderna.

Além disso, Paulo Prado pode ser visto ainda como uma figura-ponte entre o ensaísmo da década de 1920 e aquele que terá expressão maior em 1930, em obras como Raízes do Brasil (1936), de Sérgio Buarque de Holanda (1902-1987), Casa-Grande e Senzala (1933), de Gilberto Freyre e Evolução Política do Brasil (1933), de Caio Prado Júnior. Todos esses autores, vale lembrar, possuíam vínculos pessoais e de amizade com Paulo Prado.

Autor de poucos textos, Paulo Prado publica seu primeiro artigo, "O Caminho do Mar (notas para um livro)" apenas em 1922. No mesmo ano, Prado não só havia iniciado a publicação da série Eduardo Prado: para melhor conhecer o Brasil, por ele editada, com a ajuda de Capistrano, como também tinha promovido a Semana de Arte Moderna, além de ter participado da fundação da primeira revista modernista do Brasil, a Klaxon. Essa múltipla atuação e inserção, ilustrada pelos exemplos acima, entre muitos outros, revela mundos distintos que conviviam na década de 1920 e antes dela, expressos também, de alguma forma, nos textos escritos por Prado.

71 Paulo Prado é uma figura fora de lugar - que está e não está -, e isso fica muito claro nos comentadores de sua obra. Carlos Eduardo Berriel, como vimos, afirma que Prado "possuía poucas idéias que possam ser consideradas como próprias"; do mesmo modo, Alejandra Mailhe localiza "[uma] continuidad ideológica con las hipótesis y presupuestos de la generación anterior"1. . Por outro lado, para Marco Aurélio Nogueira, Prado "rompe" com o passado ao proferir palavras "duras, quase incendiárias, [que] traziam consigo desapontamento e uma postura meio iconoclasta. Vindo de onde vinham, além do mais, chegavam a chocar" ${ }^{92}$.

Não soa tão estranho, nesse sentido, o fato de Retrato do Brasil ser caracterizado como uma das obras mais representativas do modernismo brasileiro da década de $1920^{93} \mathrm{e}$, ao mesmo tempo, ser descrito como um livro totalmente dissonante da produção modernista de então $0^{94}$; ou mesmo o fato de Paulo Prado ser um autor marcado por "influências românticas" 95 e, simultaneamente, ser caracterizado como um ensaísta "avant la lettre" tempo. Conforme explica Gilberto Freyre, ele pode ser visto como "um dos casos mais curiosos de Dr. Jakyll e Mr. Hyde" 97 . Assim como o médico e o monstro do romance de Robert Louis Stevenson (1850-1894), Prado conseguiria agregar a sua personagem diferentes facetas.

Se na leitura do Brasil realizada por Paulo Prado é possível encontrar "sobrevivências de um certo conservadorismo" devido ao alinhamento do autor com as idéias de Graça Aranha ${ }^{98}$; não é possível deixar de lado o fato de Graça Aranha ter sido participante 
ativo da Semana de Arte Moderna. O "grupo modernista", conforme mostra Arnoni Prado (1983), compreende diferentes tendências, não só do ponto de vista estético, mas também do ponto de vista ideológico. Assim, a consideração da obra e do percurso de Paulo Prado parece extremamente profícua, entre outras coisas, para a construção de um quadro mais complexo e matizado do nosso modernismo, tarefa já iniciada por alguns analistas, como Tadeu Chiarelli (1995) e Sérgio Miceli (2003).

Muitas vezes, como sabemos, são as figuras “menores" que melhor ilustram uma época. No caso de Paulo Prado, creio que a observação atenta do autor e de sua obra deixa entrever importantes mediações entre universos aparentemente díspares e antagônicos - tais como o de Capistrano de Abreu e o dos modernistas paulistas; o da geração de 1870 e o da de 1922; o de Graça Aranha e o do grupo que se formava em torno da Semana de Arte Moderna, e mesmo entre as várias vertentes desse grupo em formação -, que se evidenciam também em uma escrita que fica a meio caminho entre a ciência e a arte, a história e a literatura.

\section{BIBLIOGRAFIA}

AMARAL, Aracy. Artes Plásticas na Semana de 22. 5a ed. Editora 34, São Paulo, 1998.

AMARAL, Aracy. Tarsila, sua obra e seu tempo. 3a ed. Editora 34/Edusp, São Paulo, 2003.

AMED, Fernando. As cartas de Capistrano de Abreu: sociabilidade e vida literária na belle époque carioca. Alameda, São Paulo, 2006.

ANDRADE, Mário. O Movimento Modernista. In: Aspectos da literatura brasileira. $5^{\mathrm{a}}$ ed. Martins, São Paulo, 1974, pp.231-55.

ANDRADE, Oswald. O Modernismo. Anhembi. São Paulo, v. XVII, n.49, ano X, 1954, pp.26-32.

ARAUJO, Marcelo; CAMARGOS, Márcia. Pinacoteca do Estado: a história de um museu. Pinacoteca, São Paulo, 2007.

AZEVEDO, Maria Helena. Um senhor modernista: biografia de Graça Aranha. Academia Brasileira de Letras, Rio de Janeiro, 2002.

BARATA, Mario. Sua presença na cultura brasileira. O Estado de S. Paulo. Suplemento Literário, 15 jun, 1969.

BATISTA, Marta; LIMA, Yone; LOPEZ, Telê. Brasil: 1º tempo modernista - 1917-1929. IEB, São Paulo, 1972.

BERNARDES, Maria Elena. O estandarte glorioso da cidade: Teatro Municipal de São Paulo (1911-1938), 2004. Tese de Doutorado em História. Universidade de Campinas.

BERRIEL, Carlos Eduardo. Tietê, Tejo e Sena: A Obra de Paulo Prado. Papirus, Campinas, 2000.

BOAVENTURA, Maria Eugênia. Movimento Brasileiro: contribuição ao estudo do modernismo. Comissão Estadual de Artes e Ciências Humanas, São Paulo, 1978. 
BRITO, Mário. História do modernismo brasileiro: antecedentes da semana de arte moderna. $6^{\underline{a}}$ ed. Civilização Brasileira, Rio de Janeiro, 1997.

BILAC, Olavo. Flaubert. Correio Paulistano. 24 out.1907.CALIL, Carlos Augusto (Org.). Retrato do Brasil: ensaio sobre a tristeza brasileira. $9^{\mathrm{a}}$ ed. Companhia das Letras, São Paulo, 1997, pp. 7-31.

BILAC, Olavo. (Org.). Paulística etc. $4^{\mathrm{a}}$ ed. Companhia das Letras, São Paulo, 2004, pp. 9-41.

CENDRARS, Blaise. Trop C'est Trop. Denoël, Paris, 1957.

CHIARELLI, Tadeu. Um jeca nos Vernissages. Edusp, São Paulo, 1995.

COSTA, Lúcio. Presença de Le Corbusier. In: Lucio Costa, Registro de uma Vivência. Empresa das Artes, São Paulo, 1995, pp. 144-55.

DANTAS, Arruda. Dona Olívia. Sociedade Impressora Pannartz, São Paulo, 1975.

DE LUCA, Tânia Regina. A Revista do Brasil: Um diagnóstico para a (N)ação. UNESP, São Paulo, 1999.

DI CAVALCANTI, Emiliano. Viagem da Minha Vida - $1^{\circ}$ testamento da alvorada. Civilização Brasileira, Rio de Janeiro, 1955.

DUTRA, Eliana. O Não ser e o ser outro. Paulo Prado e seu retrato do Brasil. Estudos Históricos, v.14. FGV, Rio de Janeiro, 2000, pp.233-52.

EULALIO, Alexandre. Paulo Prado: Retrato do Brasil. In: Livro Involuntário: literatura, história, matéria e memória. UFRJ, Rio de Janeiro, 1993, pp.73-87.

EULALIO, Alexandre, CALIL Carlos Augusto (Orgs.). A Aventura Brasileira de Blaise Cendrars. Edusp, São Paulo, 2001.

FERNANDES, Lygia. Mário de Andrade escreve cartas a Alceu, Meyer e outros. Editora do Autor, Rio de Janeiro, 1968.

FERRAZ, Geraldo. Perfil de um Homem e de um Livro. In: PRADO, Paulo. Retrato do Brasil: ensaio sobre a tristeza brasileira. $6^{\mathrm{a}}$ ed. José Olympio, Rio de Janeiro, 1962, pp. xi-xx.v

FREYRE, Gilberto. Pessoas, Coisas \& Animais: ensaios, conferências e artigos. In: FONSECA, E. N. (Org.). Editora Globo, Porto Alegre, 1979, pp.57-9.v

GONTIJO, Rebeca. História e historiografia nas cartas de Capistrano de Abreu. História, v. 24a, n.2.

Unicamp, Campinas, 2005, pp.159-85

HARDMAN, Francisco. Antigos Modernistas. In: NOVAES, A. (Org.). Tempo e História. Companhia das Letras/ Secretaria Municipal de Cultura, São Paulo, 1992, pp.289-305.

HARRIS, Elisabeth. Le Corbusier: Riscos Brasileiros. Editora Nobel, São Paulo, 1987.

HOMEM, Maria Cecília. O Palacete Paulistano. Martins Fontes, São Paulo, 1996.

IGREJA, Francisco. A Semana Regionalista de 1922. Edicon, São Paulo, 1989.

IUMATTI, Paulo. Caio Prado Jr., uma trajetória intelectual. Brasiliense, São Paulo, 2007.

LEITE. Dante. Luxúria, cobiça e tristeza. In: O caráter nacional brasileiro. $2^{\text {a }}$ ed. UNESP, São Paulo, 1969, pp. 260-7.

LEVI, Darrel. A Família Prado. Cultura 70, São Paulo, 1977.

LOBATO, Monteiro. Barca de Gleyre: quarenta anos de correspondência literária entre Monteiro Lobato e Godofredo Rangel. 2v., 9ª Ed. Brasiliense, São Paulo, 1959. 
MAILHE, Alejandra. Fuegos Cruzados: Estética vanguardista e ideología conservadora en Retrato do Brasil de Paulo Prado. Prismas, revista de história intelectual, n.9. UNQ, Buenos Aires, 2005, pp.35-50.

MARTINS, Wilson. 1928: Retrato do Brasil - Macunaíma - Martim Cererê. In: A Literatura Brasileira: o Modernismo (1916-1945). $2^{\mathrm{a}}$ ed. Cultrix, São Paulo, 1965, pp.197-213.

MATOS, Campos. (Org.) Eça de Queiroz- Emilia de Castro, Correspondência Epistolar. Lello e Irmão, Porto, 1995.

MICELI, Sergio. Intelectuais e a Classe Dirigente no Brasil. Difel, São Paulo, 1979.

MICELI, Sergio. Nacional e Estrangeiro. Companhia das Letras, São Paulo, 2003.

MILLIET, Sergio. Diário Crítico de Sérgio Milliet. $2^{\mathrm{a}}$ ed, 10v. Martins/ Universidade de São Paulo, São Paulo, 1981.

MORAES, Marcos Antônio. (Org.). Correspondência Mário de Andrade \& Manuel Bandeira. Edusp/IEB, São Paulo, 2000.

MOTTA FILHO, Cândido. Novos depoimentos sobre a Semana de Arte Moderna. O Estado de S. Paulo. São Paulo, 14 abr. 1962.

NOGUEIRA, Marco Aurélio. Paulo Prado: Retrato do Brasil. In: MOTA, L. (Org.) Um Banquete no Trópico. $3^{\mathrm{a}}$ ed, v.1. SENAC, São Paulo, 2001, pp. 191-213.

NOVAIS, Fernando. Raízes da Tristeza (I). Jornal de Resenhas, n. 26, 10 maio. 1997.

OLINTO, Décio. Paulo Prado, o lavrador. Correio da Manhã. 11 out. 1958.

PRADO, Antônio. 1922- Itinerários de uma Falsa Vanguarda. Os dissidentes, a Semana, o integralismo. Brasiliense, São Paulo, 1983.

PRADO, João Fernando. Paulo Prado, patrocinador da Semana de Arte Moderna. Habitat, n.7. São Paulo, 1952, pp.58-9.

PRADO, Nazareth. Antônio Prado no Império e na República. F. Briquet \& Cia, Rio de Janeiro, 1929.

PRADO, Paulo "Prefácio". In: COELHO, H. Joaquim Nabuco- Esboço Biográfico. Monteiro Lobato, São Paulo, 1922, pp. i-vii.

PRADO, Paulo. Brecheret. Revista do Brasil, v. 25, n. 98. São Paulo, 1924.

PRADO, Paulo. Cendrars. O Estado de S. Paulo. 12 jun. 1924(b).

PRADO, Paulo. Paulística: história de São Paulo. Monteiro Lobato, São Paulo, 1925.

PRADO, Paulo. Prefácio. In: ANDRADE, O. Poesia Pau Brasil. Au Sans Pareil, Paris, 1925(b), pp.5-13.

PRADO, Paulo. Retrato do Brasil: ensaio sobre a tristeza brasileira. Duprat- Mayença, São Paulo, 1928.

PRADO, Paulo. Paulística: história de São Paulo. 2ª ed. Ariel, Rio de Janeiro, 1934.

RODRIGUES, José Honório. (Org.) Correspondência de Capistrano de Abreu. 3v., Civilização Brasileira, Rio de Janeiro, 1977.

SANTOS, Cecília; PEREIRA, Margareth; SILVA, Vasco. Le Corbusier e o Brasil. Tessela e Projeto, São Paulo, 1987.

SEVCENKO, Nicolau. Orfeu Estático na Metrópole: São Paulo, sociedade e cultura nos frementes anos 20. Companhia das Letras, São Paulo, 1992.

THIOLLIER, René. Episódios de minha vida. Anhembi, São Paulo, 1956. 
WALDMAN, Thaís. À frente da Semana de Arte Moderna: a presença de Graça Aranha e Paulo Prado. Estudos Históricos, v.23, n.45. FGV/CPDOC, Rio de Janeiro, 2010, pp.71-94.

WALDMAN, Thaís. Moderno Bandeirante: Paulo Prado entre espaços e tradições. Dissertação de Mestrado em Antropologia Social. Universidade de São Paulo.

\section{NOTAS}

1. Para Berriel, "Paulo Prado possuía poucas idéias que possam ser consideradas como próprias. Elas são uma espécie de reelaboração e adaptação das teses de um grupo de intelectuais com os quais conviveu pessoalmente, e que compunham uma geração anterior à sua: mais precisamente a de seu tio, Eduardo Prado. O que está sendo dito aqui é que há uma dimensão de continuidade no Modernismo, e que essa continuidade existiu principalmente por intermédio de Paulo Prado". In: BERRIEL, Carlos Eduardo, Tietê, Tejo, Sena: A obra de Paulo Prado, p. 10-11.

2. Depois de Paulo Prado, Antônio e Maria Catarina tiveram mais sete filhos: Nazareth (1875-1949), Marina (?- 1896), Antonieta, Antônio Júnior (1880-1955), Hermínia, Luiz (1885- ?) e Silvio.

3. LEVI, Darrel. A Família Prado.

4. Carta de Emília de Castro para Eça de Queirós, em 5 de dezembro de 1891. In: MATOS, Campos (Org.) Eça de Queiroz- Emília de Castro, Correspondência Epistolar.

5. THIOLLIER, René. Episódios de minha vida, p.77.

6. MATOS, Campos. (Org.). op. cit..

7. BERRIEL, Carlos Eduardo. op. cit..

8. PRADO, Paulo. Prefácio. In: COELHO, H. Joaquim Nabuco- Esboço Biográfico, p.5.

9. CALIL, Carlos Augusto (Org.). Retrato do Brasil: ensaio sobre a tristeza brasileira.

10. PRADO, Paulo. op. cit., p.8.

11. BILAC, Olavo. Flaubert. Correio Paulistano.

12. CALIL, Carlos Augusto (Org.). op. cit..

13. PRADO, Paulo. Paulística: história de São Paulo, p.vi;

14. Carta de Maria Catarina a Paulo Prado, 22 de janeiro de 1891. In: LEVI, Darrel. op. cit..

15. Ibidem.

16. THIOLLIER, René. op. cit..

17. As cartas de Capistrano a Paulo Prado somam 116 epístolas. Infelizmente, as cartas escritas por Prado não foram encontradas ainda, cf. RODRIGUES, José Honório. (Org.) Correspondência de Capistrano de Abreu. Sobre a correspondência trocada entre Paulo Prado e Capistrano de Abreu, cf. AMED, Fernando. As cartas de Capistrano de Abreu: sociabilidade e vida literária na belle époque carioca e GONTIJO, Rebeca. História e historiografia nas cartas de Capistrano de Abreu.

18. Carta de Capistrano de Abreu a João Lúcio de Azevedo, 22 de junho de 1918. In: RODRIGUES, José Honório (Org.) Correspondência de Capistrano de Abreu, v.3, p.99.

19. Sobre as interlocuções estabelecidas entre Paulo Prado e Graça Aranha, cf. DUTRA, Eliana. $O$ Não ser e o ser outro. Paulo Prado e seu retrato do Brasil e WALDMAN, Thaís. À frente da Semana de Arte Moderna: a presença de Graça Aranha e Paulo Prado.

20. PRADO, Paulo. Brecheret. Revista do Brasil, v. 25, n. 98, p.180.

21. SEVCENKO, Nicolau. Orfeu Estático na Metrópole: São Paulo, sociedade e cultura nos frementes anos 20.

22. ANDRADE, Mário. O Movimento Modernista. In: Aspectos da literatura brasileira, p.237.

23. DI CAVALCANTI, Emiliano. Viagem da Minha Vida - $1^{\circ}$ testamento da alvorada, p.117. 
24. Cf. BRITO, Mário. História do modernismo brasileiro: antecedentes da semana de arte moderna; AMARAL, Aracy. Artes Plásticas na Semana de 22; MARTINS, Wilson. 1928: Retrato do Brasil Macunaíma - Martim Cererê; entre outros.

25. Cf. Igreja, Francisco. A Semana Regionalista de 1922; Hardman, Francisco. Antigos Modernistas; Chiarelli, Tadeu. Um jeca nos Vernissages; Miceli, Sergio. Nacional e Estrangeiro; entre outros.

26. MOTTA FILHO, Cândido. Novos depoimentos sobre a Semana de Arte Moderna. O Estado de S. Paulo.

27. EULALIO, Alexandre. Paulo Prado: Retrato do Brasil. In: EULALIO, Alexandre. Livro Involuntário: literatura, história, matéria e memória.

28. IANDRADE, Mário. op.cit., p.234-235.

29. ANDRADE, Oswald. O Modernismo. Anhembi, p.28.

30. Ibidem.

31. AZEVEDO, Maria Helena. Um senhor modernista: biografia de Graça Aranha.

32. MICELI, Sergio. Nacional e Estrangeiro, p.143.

33. Antônio Prado é o prefeito que mais tempo ficou no cargo, completando doze anos de administração - entre 1899 e 1911 -, função que exerce junto com a presidência de diversas empresas como: Banco do Comércio e Indústria, Companhia Paulista de Estradas de Ferro, Curtume Água Branca, Frigorífico Barretos, Vidraria Santa Marina, Automóvel Clube e os negócios imobiliários no Guarujá.

34. PRADO, Nazareth. Antônio Prado no Império e na República, p.376.

35. BERNARDES, Maria Elena. O estandarte glorioso da cidade: Teatro Municipal de São Paulo (1911-1938).

36. SEVCENKO, Nicolau. op. cit..

37. Como resultado dessa negociação, fica determinada uma aproximação do Brasil com os aliados na Grande Guerra e a transferência para a França dos navios alemães apreendidos nas costas brasileiras, em troca da compra de dois milhões de sacas de café - operação que seria intermediada pela Companhia Prado Chaves.

38. ARAUJO, Marcelo; CAMARGOS, Márcia. Pinacoteca do Estado: a história de um museu.

39. SEVCENKO, Nicolau. op. cit., p.235.

40. IUMATTI, Paulo. Caio Prado Jr., uma trajetória intelectual.

41. SEVCENKO, Nicolau. op. cit..

42. Ibidem, p.242.

43. PRADO, Paulo. Prefácio. In: ANDRADE, O. Poesia Pau Brasil, p.5.

44. PRADO, João Fernando. Paulo Prado, patrocinador da Semana de Arte Moderna. Habitat, n.7.

45. Carta de Paulo Prado a Mário de Andrade, 13 de julho de 1927. Arquivo Mário de Andrade, (IEB/USP), MA-C-CPL5935.

46. FREYRE, Gilberto. Pessoas, Coisas \& Animais: ensaios, conferências e artigos.

47. Oswald de Andrade também irá se impressionar com a fazenda São Martinho, a qual dedica uma série de quinze poemas de sua Poesia Pau Brasil (1925).

48. CALIL, Carlos Augusto (Org.). Paulística etc.

49. MICELI, Sergio. op. cit..

50. Ibidem.

51. Entrevista concedida por Oswald de Andrade a Arruda Dantas, em janeiro de 1950. In: DANTAS, Arruda. Dona Olívia, p.73.

52. É possível consultar os quadros de Léger que pertenceram a Prado no catálogo redigido por Michelle Richet e Claude Langier para a exposição de Léger no Grand Palais parisiense, realizada de outubro de 1971 e janeiro de 1972. In: EULALIO, Alexandre; CALIL Carlos Augusto (Orgs.). A Aventura Brasileira de Blaise Cendrars.

53. CENDRARS, Blaise. Trop C'est Trop.

54. CALIL, Carlos Augusto (Org.). Paulística etc.

55. EULALIO, Alexandre; CALIL Carlos Augusto (Orgs.). op. cit.. 
56. AMARAL, Aracy. Artes Plásticas na Semana de 22.

57. PRADO, Paulo. Cendrars. 0 Estado de S. Paulo.

58. Publicado em 1931, na oitava parte - Poètes- de Aujourd hui, dedicada a Paulo Prado.

59. “E.F.C.B.”, 1924, óleo/tela 142 x 127 cm, Coleção Museu de Arte Contemporânea, SP.

60. AMARAL, Aracy. op. cit..

61. BOAVENTURA, Maria Eugênia. Movimento Brasileiro: contribuição ao estudo do modernismo, p.115.

62. EULALIO, Alexandre; CALIL Carlos Augusto (Orgs.). op. cit..

63. Cartão postal de Blaise Cendrars a Le Corbusier, 13 de junho de 1926. In: Ibidem, p. 313.

64. HARRIS, Elisabeth. Le Corbusier: Riscos Brasileiros.

65. COSTA, Lúcio. Presença de Le Corbusier. In: COSTA, Lucio. Registro de uma Vivência, p.144.

66. SANTOS, Cecília; PEREIRA, Margareth; SILVA, Vasco. Le Corbusier e o Brasil.

67. AMARAL, Aracy. Tarsila, sua obra e seu tempo.

68. ANDRADE, Mário. op. cit..

69. ANDRADE, Oswald. op. cit., p.28.

70. HOMEM, Maria Cecília. O Palacete Paulistano.

71. MILLIET, Sergio. Diário Crítico de Sérgio Milliet.

72. SEVCENKO, Nicolau. op. cit..

73. "A Onda", 1915/17, óleo s/ madeira, 26,5 x 36, 2cm, Coleção Sérgio Fadel, RJ. In: BATISTA, Marta; LIMA, Yone; LOPEZ, Telê. Brasil: 1ํ tempo modernista - 1917-1929.

74. "São Paulo", 1924, óleo s/ tela, 67 x 90cm, Pinacoteca do Estado de São Paulo. In: BARATA, Mario. Sua presença na cultura brasileira. O Estado de S. Paulo.

75. "O Ovo ou Urutu", 1928, óleo s/ tela, 60 x 72cm, Coleção Gilberto Chateaubriand, RJ. In: Ibidem.

76. “Cabeça de Mulher”, 1920-21, escultura de mármore. In: CALIL, Carlos Augusto. Paulística etc.

77. "Safo", 1920-21, escultura em bronze, $42 \mathrm{~cm}$ de altura. In: Ibidem.

78. "Virgem (Vierge à l'enfant)", 1923-24, escultura de mármore. In: Ibidem.

79. "Ritmo", 1924, escultura em bronze. In: Ibidem.

80. "Sonho de uma prostituta", 1930/32, aquarela sobre papel, 55,5 x $50 \mathrm{~cm}$, Coleção Chateaubriand Bandeira de Mello, PB. In: FERRAZ, Geraldo. Perfil de um Homem e de um Livro.

81. Idealizado e batizado por Quirino da Silva, o Salão de Maio teve três edições na cidade de São Paulo, entre 1937 e 1939. Seu objetivo era criar um espaço para a arte moderna nacional, assim como promover o intercâmbio com a produção internacional. Por ocasião do $1^{\circ}$ Salão, Prado aconselha Ferraz a intitular o quadro "Sonho de uma Prostituta" como "Composição no 1", evitando assim possíveis escândalos. In: Ibidem.

82. SEVCENKO, Nicolau. op. cit..

83. OLINTO, Décio. Paulo Prado, o lavrador. Correio da Manhã.

84. MORAES, Marcos Antônio. (Org.). Correspondência Mário de Andrade \& Manuel Bandeira.

85. DE LUCA, Tânia Regina. A Revista do Brasil: Um diagnóstico para a (N)ação.

86. MARTINS, Wilson. 1928: Retrato do Brasil - Macunaíma - Martim Cererê. In: A Literatura Brasileira: o Modernismo (1916-1945).

87. Carta de Monteiro Lobato a Godofredo Rangel, 7 de abril de 1924. In: LOBATO, Monteiro. Barca de Gleyre: quarenta anos de correspondência literária entre Monteiro Lobato e Godofredo Rangel, v.2, p. 264.

88. Carta de Mário de Andrade a Augusto Meyer, 23 de janeiro de 1931. In: FERNANDES, Lygia. Mário de Andrade escreve cartas a Alceu, Meyer e outros, p.82.

89. Mário de Andrade esclarece um pouco a situação: "Está claro que se a gente pedisse tenho certeza que Paulo Prado sustentaria a revista com o dinheiro dele, mas isso não nos conviria, você compreende, porque nos deixava ao Alcântara e a mim, numa situação indiscutível de subalternidade que não seria envergonhante eu sei, mas era sempre desagradável, quanto à orientação da revista". In: Ibidem, p.96. 
90. MICELI, Sergio. Intelectuais e a Classe Dirigente no Brasil.

91. MAILHE, Alejandra. Fuegos Cruzados: Estética vanguardista e ideología conservadora en Retrato do Brasil de Paulo Prado. Prismas, revista de história intelectual, p.36.

92. NOGUEIRA, Marco Aurélio. Paulo Prado: Retrato do Brasil. In: MOTA, L. (Org.) Um Banquete no Trópic, p.198.

93. MARTINS, Wilson. op. cit..

94. LEITE. Dante. Luxúria, cobiça e tristeza. In: O caráter nacional brasileiro.

95. DUTRA, Eliana. O Não ser e o ser outro. Paulo Prado e seu retrato do Brasil. Estudos Históricos, p. 234-5.

96. NOVAIS, Fernando. Raízes da Tristeza (I). Jornal de Resenhas, n. 26, p.741.

97. FREYRE, Gilberto. op. cit., p.57.

98. DUTRA, Eliana. op. cit., p. 223.

\section{RESUMOS}

Além de ser um dos maiores exportadores e produtores de café da época, Paulo Prado é autor de dois livros sobre a história de São Paulo e a formação do povo brasileiro. Publicou textos em importantes periódicos, (re)editou documentos inéditos sobre o período colonial, participou da fundação e do controle de revistas modernistas, e se fez presente como um dos principais organizadores e financiadores da Semana de 1922. Foi também um elo fundamental entre os modernistas e um grupo de intelectuais que compõem uma geração anterior a sua, que ele conhece na Europa, por intermédio de seu tio, Eduardo Prado. Possui ainda um forte vínculo com Capistrano de Abreu, um marco da moderna historiografia brasileira. Paulo Prado mostra-se assim um importante mediador entre diferentes universos, sendo este o foco do presente artigo.

Outre qu'il fut l'un des principaux producteurs et exportateurs de café de son époque, Paulo Prado est aussi connu comme l'auteur de deux livres sur l'histoire de la ville de São Paulo et sur la formation du peuple brésilien. Il publia des textes dans d'importantes revues, fut l'éditeur de documents inédits sur la période coloniale, collabora à la fondation et à la direction de plusieurs revues modernistes et devint l'un des principaux organisateurs et mécène de la Semaine d'Art Moderne de 1922. Il fut également un lien fondamental entre les modernistes et un groupe d'intellectuels de la génération précédente, qu'il rencontra en Europe par l'intermédiaire de son oncle, Eduardo Prado. Il fut de plus particulièrement proche de Capistrano de Abreu, un jalon de l'historiographie brésilienne moderne. Paulo Prado joua ainsi un rôle important de médiateur entre différents univers, ce qui constitue le thème de cet article.

\section{ÍNDICE}

Mots-clés: Prado (Paulo), Semana de Arte Moderna, modernisme, tradition, pensée sociale brésilienne

Palavras-chave: Prado (Paulo), Semana de Arte Moderna, modernismo, tradição, pensamento social brasileiro 


\section{AUTOR}

\section{THAÍS CHANG WALDMAN}

Mestre em Antropologia Social pela Universidade de São Paulo (USP)

tatawald[at]yahoo.com.br 